\title{
Epidermal Growth Factor Based Targeted Toxin for the Treatment of Bladder Cancer
}

\author{
ANIE PRISCILLA MASILAMANI ${ }^{1,2}$, ALEXANDRA FISCHER $^{1,2}$, \\ SUSANNE SCHULTZE-SEEMANN ${ }^{1,2}$, IRINA KUCKUCK ${ }^{1,2}$, ISIS WOLF ${ }^{1,2}$, \\ FRANZ FRIEDRICH DRESSLER ${ }^{3}$, CHRISTIAN GRATZKE ${ }^{1,2}$ and PHILIPP WOLF ${ }^{1,2}$ \\ ${ }^{1}$ Faculty of Medicine, University of Freiburg, Freiburg, Germany; \\ ${ }^{2}$ Department of Urology, Antibody-Based Diagnostics and Therapies, \\ Medical Center-University of Freiburg, Freiburg, Germany; \\ ${ }^{3}$ Insitute of Pathology, University Medical Center Schleswig-Holstein, Lübeck, Germany
}

\begin{abstract}
Background/Aim: Reports on over-expression of the epidermal growth factor receptor (EGFR) in bladder cancer and its function in tumorigenesis have suggested to target this antigen. Materials and Methods: We generated the targeted toxin EGF-PE4O consisting of the human epidermal growth factor (EGF) as the binding domain and PE40, a truncated version of Pseudomonas Exotoxin $A$, as the toxin domain. EGF-PE40 was tested on EGFR-expressing bladder cancer cells in view of binding via flow cytometry, and cytotoxicity via WST viability assay. Induction of apoptosis was examined by western blot. Results: The targeted toxin specifically triggered cytotoxicity in the bladder cancer cells with $50 \%$ inhibitory concentration $\left(I C_{50}\right)$ values in the low nanomolar or picomolar range, and was about 1,250- to 1,500-fold more cytotoxic than the EGFR inhibitor erlotinib. Cytotoxicity of EGF-PE4O was based on the induction of apoptosis. Conclusion: EGF-PE4O represents a promising candidate for the future treatment of bladder cancer.
\end{abstract}

Bladder cancer (BC) is the 10th most common cancer worldwide. Approximately 573,000 new cases and 213,000 deaths from this tumor are expected every year, with highest incidence rates in Europe and North America (1). About 70\% of $\mathrm{BC}$ cases are non-muscle invasive at the time of diagnosis.

This article is freely accessible online.

Correspondence to: Philipp Wolf, Department of Urology, Medical Center - University of Freiburg, Breisacher Str. 66, 79106 Freiburg, Germany. Tel: +49 76127028921, e-mail: philipp.wolf@uniklinikfreiburg.de

Key Words: Bladder cancer, epidermal growth factor, epidermal growth factor receptor, targeted toxin, Pseudomonas Exotoxin A.
They are treated by transurethral resection of the tumor (TURBT) followed by adjuvant intravesical treatment with Bacillus Calmette-Guerin (BCG) or mitomycin (2). However, in about $70 \%$ of patients the tumor recurs and in $10-20 \%$ of these cases it progresses to muscle-invasive BC (3). Only $50 \%$ of patients with muscle-invasive BC survive 5 years despite undergoing radical cystectomy (4). For patients with metastatic disease, cisplatin-based chemotherapy is the standard of care, conferring a median overall survival of 13-16 months $(5,6)$. Despite therapeutic progress in recent years, e.g. with immune checkpoint inhibitors $(7,8), \mathrm{BC}$ is still characterized by a high recurrence rate and a complex and expensive treatment with numerous local and systemic side effects (9). Therefore, new targeted treatment options are urgently needed.

In recent years, EGFR has aroused great interest as new target for the treatment of BC. EGFR was mainly detected in the membrane of $\mathrm{BC}$ cells and is only sparsely distributed in the cytoplasm (10). EFGR expression was detected in 55$58 \%$ of bladder transitional cell carcinoma samples $(10,11)$ and in $75 \%$ of invasive BC tissues (12). In contrast, only $10 \%$ of non-cancer bladder mucous membrane tissues samples were found to be EGFR positive (10).

EGFR signaling has been shown to regulate cell proliferation, apoptosis, angiogenesis, invasion, and tumor metastasis in preclinical models of transitional cell carcinoma (TCC) of the bladder (13). EGFR expression was positively correlated with clinical stage, pathologic grade, and recurrence of $\mathrm{BC}$, and negatively correlated with prognosis and survival $(10,14)$.

Targeting EGFR with the monoclonal antibody Cetuximab, however, yielded disappointing results in patients with $\mathrm{BC}$, failed to prevent disease progression and developed drug resistance and toxicities $(15,16)$. Preliminary data from a phase II clinical trial examining the effectiveness of neoadjuvant EGFR inhibition in muscle-invasive $\mathrm{BC}$ 
(clinical stage T2) by the inhibitor erlotinib suggested that it might have single-agent activity (17).

Targeted toxins might represent alternatives in the immunotherapy of BC. They consist of a ligand as binding domain and a toxin of bacterial, fungal, plant, or animal origin as active domain (18). In general, the ligand domain binds to target antigens on the surface of cancer cells and, after internalization, the toxin domain can unleash its enzymatic activity and trigger cancer cell death (19). One prominent toxin for the construction of targeted toxins is Pseudomonas Exotoxin A (PE). PE is a virulence factor from the bacterium Pseudomonas aeruginosa (20). PE is a 638 aa protein with several functional domains. Domain Ia (aa 1-252) binds to CD91, a receptor, which is omnipresent on the surface of eukaryotic cells. Domain II (aa 253-364) includes a furin cleavable motif and enables the toxin to cross cellular membranes. Domains Ib (aa 365-404) and III (aa 405-613) have ADP-ribosyl transferase activity and a KDEL-like motif at the C-terminus. PE binds to CD91 on host cells and is internalized into endosomes, where it is cleaved by furin. The C-terminal part of the protein, consisting of domain II, Ib, and III is $40 \mathrm{kDa}$ in size and is therefore also called PE40. PE40 can bind via its KDELmotif to KDEL-receptors of the Golgi apparatus. It is then transported retrogradely to the ER and secreted into the cytosol. On the ribosomes, it specifically ADP-ribosylates the eukaryotic elongation factor 2 (eEF-2). ADPribosylation of eEF-2 leads to an inhibition of protein biosynthesis and to apoptosis of the target cells [rev. in (21)].

In the present study, we generated and analyzed the new targeted toxin EGF-PE40, consisting of the human EGF ligand as the binding domain and PE40 as the toxin domain, in view of binding, cytotoxicity, and induction of apoptosis on EGFR expressing BC cells.

\section{Materials and Methods}

Cell lines and reagents. Human urinary BC cell lines T24 (transitional cell carcinoma) and HT-1376 (grade 3, carcinoma) were purchased from the American Type Culture Collection (Manassas, VA, USA) and cultured in Dulbecco's modified Eagle medium (Gibco, Invitrogen, Karlsruhe, Germany) with $10 \%$ fetal calf serum (Biochrom, Berlin, Germany) and penicillin/streptomycin $(100 \mathrm{U} / \mathrm{ml}, 100 \mathrm{mg} / \mathrm{l})$ at $37^{\circ} \mathrm{C}$ and $5 \% \mathrm{CO}_{2}$. Verification of the cell lines was performed by short tandem repeat analysis (CLS GmbH, Eppelheim, Germany). CHO cell line was cultured in Ham's F12 nutrient mix medium (Gibco, Invitrogen) with $10 \%$ fetal calf serum (Biochrom) and penicillin/streptomycin $(100 \mathrm{U} / \mathrm{ml}, 100 \mathrm{mg} / \mathrm{l})$ at $37^{\circ} \mathrm{C}$ and $5 \% \mathrm{CO}_{2}$ as control. Erlotinib $\mathrm{HCl}$ (Selleck Chemicals Llc, Houston, TX, USA) was dissolved as $4 \mathrm{mg} / \mathrm{ml}$ stock solution in DMSO and stored at $-80^{\circ} \mathrm{C}$ until use.

Generation and purification of EGF and EGF-PE40. The ligand EGF and the targeted toxin EGF-PE40 were cloned into the expression vector pHOG21, periplasmatically expressed in E. coli XL-1 blue bacteria, and purified by immobilized affinity chromatography (IMAC) as described before (22). Purified EGF and EGFR were detected by SDS-PAGE and protein content was determined by Nanodrop analysis (Thermo Fisher Scientific, Waltham, MA, USA).

Western blot analyses. To determine EGFR expression in the target cells, cells were lysed in RIPA buffer as described previously (22) and western blot analysis was done on whole cell lysates $(50 \mu \mathrm{g} / \mathrm{lane})$ using EGFR rabbit polyclonal antibody (pAb) (Santa Cruz Biotechnology, Dallas, TX, USA) and HRP-labeled goat anti-rabbit pAb (Dako Denmark A/S, Glostrup, Denmark). $\beta$-Actin was used as a loading control and detected by HRP-conjugated $\beta$-Actin rabbit $\mathrm{pAb}$ (Cell Signaling Technology Europe, Leiden, the Netherlands). Expression of EGF and EGF-PE40, containing a c-myc tag was verified by western blot using the HRP-labeled anti-cmyc antibody (Roche laboratories) or an anti-PE rabbit pAb (Sigma) and HRPlabeled goat anti-rabbit pAb (Dako Denmark A/S, Glostrup, Denmark). To detect apoptosis, cell lysates before and after $48 \mathrm{~h}$ incubation with $2 \mathrm{nM}$ EGF-PE40 were blotted and poly-ADP-ribosepolymerase (PARP) cleavage was detected by rabbit anti-PARP pAb (Cell Signaling Technology Europe) and HRP-labeled goat anti-rabbit $\mathrm{pAb}$ (Dako). Visualization of the protein bands was carried out after developing the membranes with an enhanced chemiluminescence (ECL) system (Clarity ${ }^{\mathrm{TM}}$ Western ECL Substrate, Bio-Rad Laboratories, Inc., Hercules, CA, USA), using the ChemiDoc ${ }^{\mathrm{TM}}$ MP Imaging System and the software Image $\mathrm{Lab}^{\mathrm{TM}}$.

Flow cytometry. Binding of EGF and EGF-PE40 on the target cells was examined by flow cytometry as described before (23). Bound EGF and targeted toxins were detected via rabbit anti-His-tag $\mathrm{mAb}$ (Cell Signaling Technology Europe, Leiden, The Netherlands) and goat anti-rabbit IgG-PE (Southern Biotech, Birmingham, AL, USA). Stained cells were analyzed with a FACS Calibur flow cytometer and the software CellQuest Pro (BD Biosciences, Heidelberg, Germany).

WST-1 cell viability assay. Cell viability after targeted toxin or erlotinib treatment was quantified by the colorimetric WST-1-Assay (Roche Diagnostics, Mannheim, Germany) according to the standard protocol. $50 \%$ inhibitory concentrations $\left(\mathrm{IC}_{50}\right)$ values of WST-1 data were calculated for each cell line using GraphPad Prism 7 software by non-linear regression [(inhibitor) vs. normalized response].

\section{Results}

Firstly, expression of the $170 \mathrm{kDa}$ protein EGFR on the BC cell lines T24 and HT-1376 was verified by western blot analysis. The control cell line $\mathrm{CHO}$ was found to be human EGFR negative (Figure 1A). After periplasmatic expression in E. coli XL-1 blue bacteria and purification via IMAC, the ligand EGF $(8.4 \mathrm{kDa})$ and the targeted toxin EGF-PE40 $(49.2 \mathrm{kDa})$ were obtained in high purity of $>90 \%$ as determined by SDS-PAGE (Figure 1B). Expression of the proteins was verified by western blot analysis (Figure 1C and D). Binding of EGF and EGF-PE40 was demonstrated by flow cytometry on T24 and HT-1376 cells. No binding with both constructs was seen on EGFR-negative $\mathrm{CHO}$ cells 
A

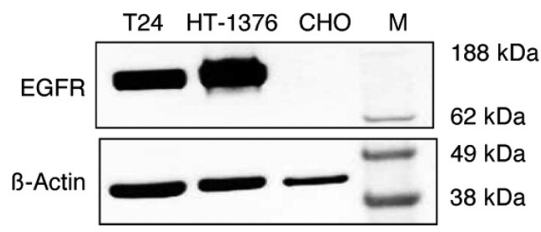

B

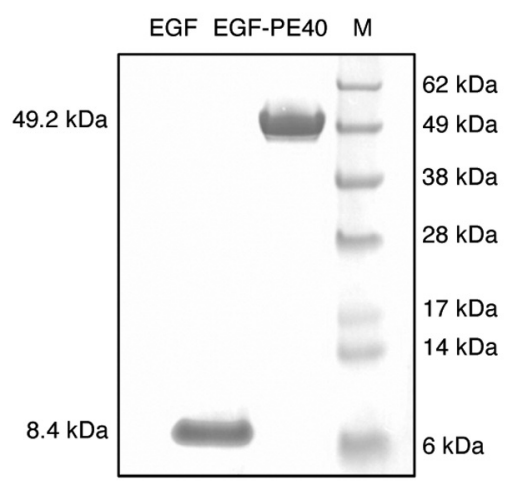

C EGF EGF-PE40 M

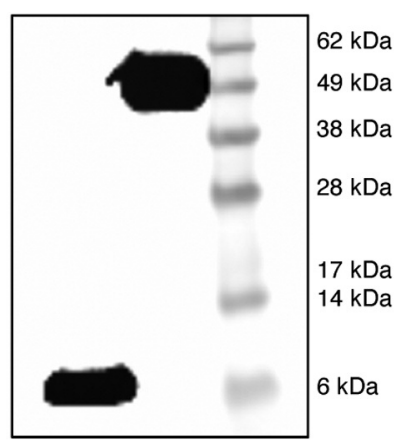

D

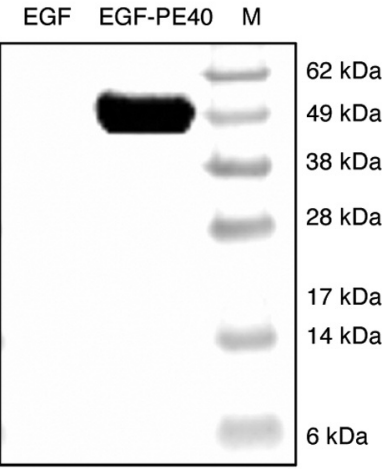

E

T24
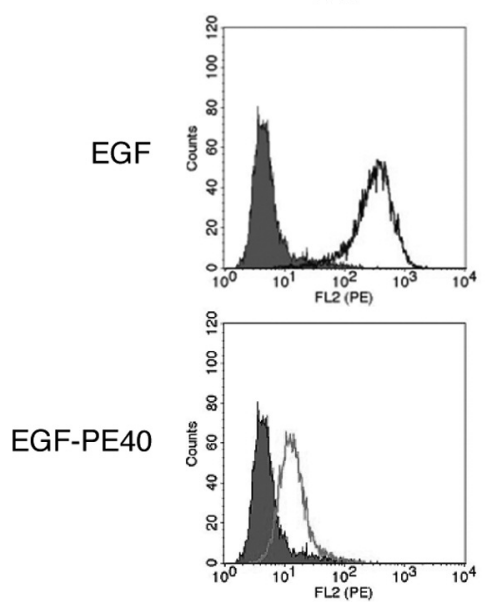

HT-1376
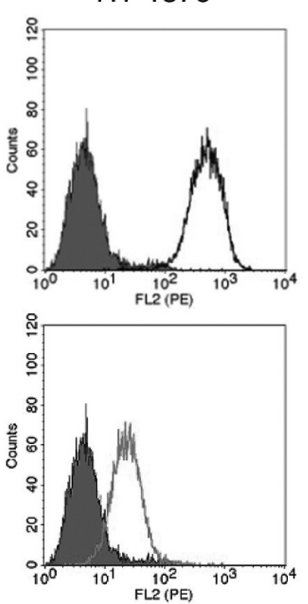
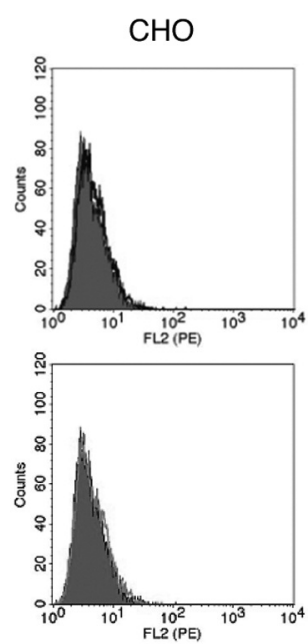

Figure 1. Generation and characterization of the EGF ligand and the anti-EGFR targeted toxin EGF-PE40 on bladder cancer (BC) cells. (A) EGFR expression in BC cells as shown by western blot analysis. EGFR negative CHO cells served as control. (B) SDS-PAGE of the ligand EGF and the targeted toxin EGF-PE40 after periplasmatic expression in E. coli and purification via IMAC. (C) Western blot analysis of EGF and EGF-PE40 using detection antibodies against the c-myc tag or (D) against the PE4O domain. (E) Binding of EGF and EGF-PE4O to EGFR-positive T24 and HT-1376 BC cells as analysed by flow cytometry with secondary detection antibody alone in grey. CHO cells served as controls.

(Figure 1E). This proved that addition of the PE40 domain did not impair the specificity of EGF.

The targeted toxin elicited a high and specific cytotoxicity in T24 and HT-1376 cells with $\mathrm{IC}_{50}$ values of $2.009 \mathrm{nM}$ and 0.281 $\mathrm{nM}$ after $48 \mathrm{~h}$, respectively. In CHO cells, no cytotoxicity was detected up to a maximal targeted toxin concentration of $10 \mathrm{nM}$
(Figure 2A). PARP cleavage demonstrated that the targeted toxin induced apoptosis in the BC cells (Figure 2B). With the EGFR inhibitor erlotinib, $\mathrm{IC}_{50}$ values of $>2.5 \mu \mathrm{M}$ and $0.42 \mu \mathrm{M}$ were calculated on T24 and HT-1376 cells, respectively (Figure 2C). Thus, EGF-PE40 showed an about 1,250 to 1,500-fold enhanced cytotoxicity compared to erlotinib. 
A

T24

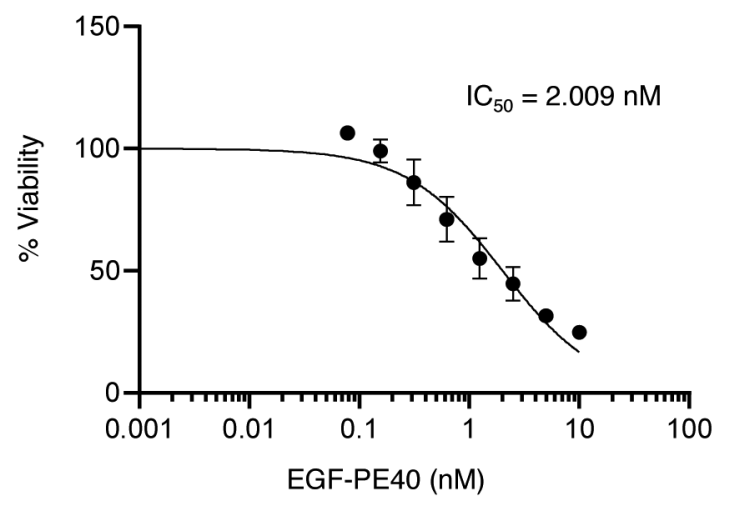

HT-1376

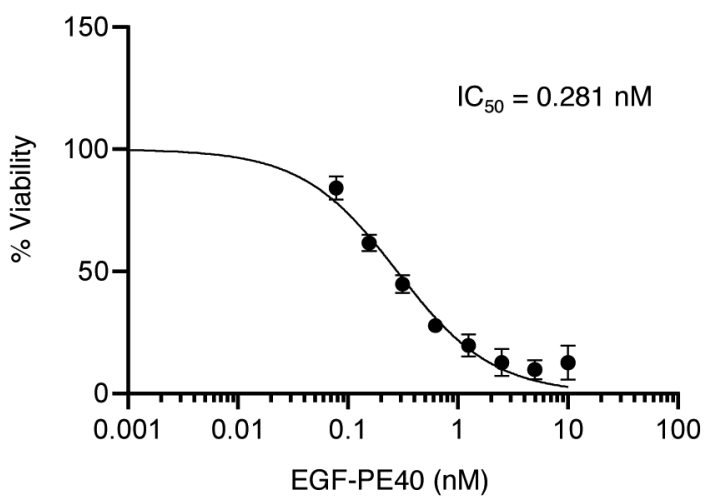

$\mathrm{CHO}$

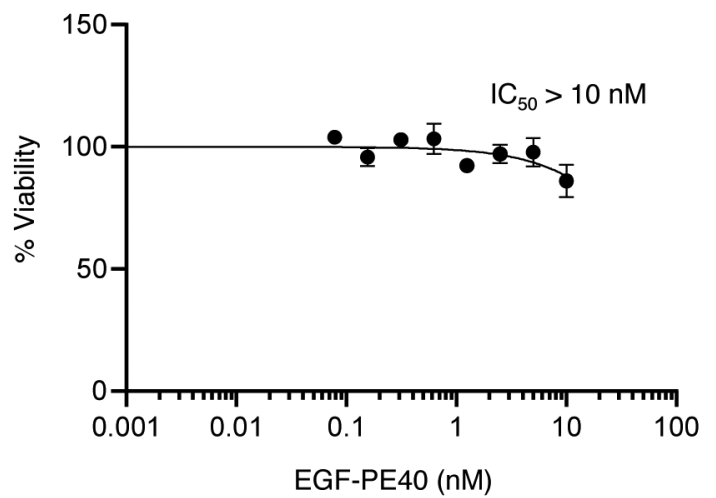

B

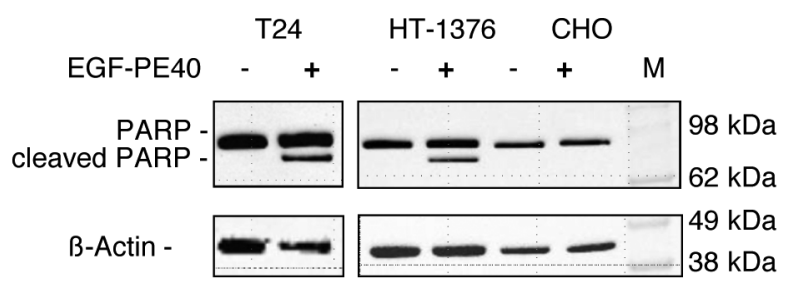

C

T24

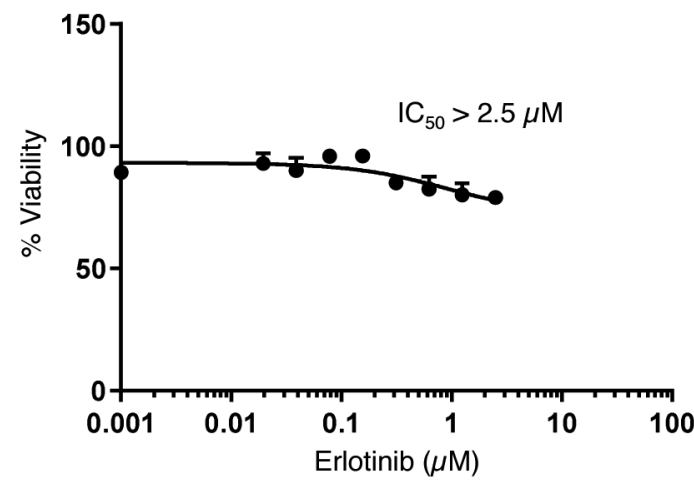

HT-1376

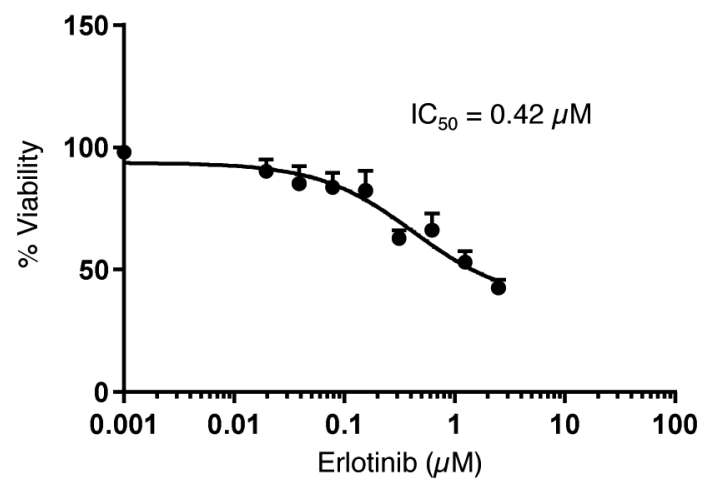

Figure 2. Cytotoxicity of EGF-PE4O and the EGFR inhibitor erlotinib in bladder cancer cells. (A) Cytotoxicity of EGF-PE40 in T24 and HT-1376 bladder cancer (BC) cells as measured by WST-1 tests. CHO cells were used as control. (B) Induction of apoptosis, marked by cleavage of polyADP-Ribose-Polymerase (PARP), in BC cells after incubation with $2 \mathrm{nM} \mathrm{EGF-PE40} \mathrm{as} \mathrm{shown} \mathrm{by} \mathrm{western} \mathrm{blot} \mathrm{analysis.} \mathrm{(C)} \mathrm{Cytotoxicity} \mathrm{of} \mathrm{the}$ EGFR inhibitor erlotinib on T24 and HAT-1376 cells as measured by WST-1 tests. Mean $\pm S D$ of three independent experiments. M: Marker. 


\section{Discussion}

Our study demonstrates that EGF can be used for the effective targeting of EGFR on the surface of BC cells. The targeted toxin EGF-PE40 elicited a specific and concentration-dependent killing of EGFR-expressing BC cells based on the induction of apoptosis. Compared to the inhibitor erlotinib, which shows stoichiometric one to one binding with the tyrosine kinase moiety of EGFR, EGFPE40 caused a 1,250- to 1,500-fold increased cytotoxicity in T24 and HT-1376 cells, respectively. This underlines the high potential of biologically active targeted toxins in the fight against $\mathrm{BC}$.

Our study conforms to other studies in which targeted toxins against EGFR were produced and tested on BC cells. Sarosdy et al. developed the targeted toxin TP-40, consisting of TGF- $\alpha$ as the binding domain and PE40, which showed a high sensitivity in murine and human BC cells as well as primary tumors, including well-differentiated tumors, from $\mathrm{BC}$ patients (24). In a recent study, a targeted toxin was published consisting of the EFG ligand and Anthrax toxin from Bacillus anthracis. The immunotoxin was internalized within few minutes into BC cells of human, mouse or dog origin and killed them with $\mathrm{LD}_{50}$ values of $<1 \mathrm{nM}$. Moreover, the immunotoxin induced an about $30 \%$ average tumor reduction after one intravesical application cycle in dogs with BC (25).

Future clinical application of EGF-PE40 in patients with $\mathrm{BC}$ must be considered not only in terms of specificity and efficacy, but also against the background of possible side effects. These include a possible immunogenicity of the targeted toxin leading to neutralization by anti-drug antibodies (ADA) and evocation of allergic reactions as well as on target/off tumor toxicities due to EGFR expression on various normal tissues. Immunogenicity of the EGF ligand is not expected, since EGF is of human origin. Immunogenicity of the PE40 domain can be reduced by de-immunization, i.e. elimination of immunodominant B- and T cell epitopes, or combination with immune modulating drugs [rev. in (26)]. Instillation of EGF-PE40 into the bladder could reduce systemic distribution and diminish or avoid on target/off tumor activities. Moreover, combination therapies with drugs that act synergistically with EGF-PE40 could reduce side effects. In studies with PE40 based immunotoxins targeting the prostate specific membrane antigen (PSMA) on prostate cancer cells, we showed synergisms with docetaxel or with the BH3 mimetic ABT-737, which led to an enhanced down-regulation of anti-apoptotic Bcl-2 proteins (23, 27, 28). Future experiments will show whether the effectivity of EGF-PE40 against $\mathrm{BC}$ cells can be increased in combination with chemotherapy or BH3 mimetics.

Taken together, the targeted toxin EGF-PE40 represents a promising candidate for the specific treatment of $\mathrm{BC}$ and merits additional research activities to be developed further towards the clinic.

\section{Conflicts of Interest}

The Authors declare no conflicts of interest regarding this study.

\section{Authors' Contributions}

P.W.: project administration; A.P.M., P.W.: study design; A.P.M., A.F., S.S.S., I.K., I.W.: performance of experiments, data collection; A.P.M., I.W., F.F.D., C.G., P.W.: writing, editing and reviewing of the manuscript. All Authors have approved the contents of the article.

\section{Acknowledgements}

This work was supported by a grant of the German Research Foundation (Grant No. WO 2178/2-1 to P.W.).

\section{References}

1 Sung H, Ferlay J, Siegel RL, Laversanne M, Soerjomataram I, Jemal A and Bray F: Global Cancer Statistics 2020: GLOBOCAN estimates of incidence and mortality worldwide for 36 cancers in 185 countries. CA Cancer J Clin 71(3): 209249, 2021. PMID: 33538338. DOI: 10.3322/caac.21660

2 Peyton CC, Chipollini J, Azizi M, Kamat AM, Gilbert SM and Spiess PE: Updates on the use of intravesical therapies for nonmuscle invasive bladder cancer: how, when and what. World J Urol 37(10): 2017-2029, 2019. PMID: 30535583. DOI: 10.1007/s00345-018-2591-1

3 Kaufman DS, Shipley WU and Feldman AS: Bladder cancer. Lancet 374(9685): 239-249, 2009. PMID: 19520422. DOI: 10.1016/S0140-6736(09)60491-8

4 Stein JP, Lieskovsky G, Cote R, Groshen S, Feng AC, Boyd S, Skinner E, Bochner B, Thangathurai D, Mikhail M, Raghavan $\mathrm{D}$ and Skinner DG: Radical cystectomy in the treatment of invasive bladder cancer: long-term results in 1,054 patients. J Clin Oncol 19(3): 666-675, 2001. PMID: 11157016. DOI: 10.1200/JCO.2001.19.3.666

5 Bellmunt J, von der Maase H, Mead GM, Skoneczna I, De Santis M, Daugaard G, Boehle A, Chevreau C, Paz-Ares L, Laufman LR, Winquist E, Raghavan D, Marreaud S, Collette S, Sylvester R and de Wit R: Randomized phase III study comparing paclitaxel/cisplatin/gemcitabine and gemcitabine/cisplatin in patients with locally advanced or metastatic urothelial cancer without prior systemic therapy: EORTC Intergroup Study 30987. J Clin Oncol 30(10): 1107-1113, 2012. PMID: 22370319. DOI: 10.1200/JCO.2011.38.6979

6 von der Maase H, Sengelov L, Roberts JT, Ricci S, Dogliotti L, Oliver T, Moore MJ, Zimmermann A and Arning M: Long-term survival results of a randomized trial comparing gemcitabine plus cisplatin, with methotrexate, vinblastine, doxorubicin, plus cisplatin in patients with bladder cancer. J Clin Oncol 23(21): 4602-4608, 2005. PMID: 16034041. DOI: 10.1200/JCO.2005.07.757

7 Mori K, Pradere B, Moschini M, Mostafaei H, Laukhtina E, Schuettfort VM, Sari Motlagh R, Soria F, Teoh JYC, Egawa S, Powles T, Shariat SF and European Association of UrologyYoung Academic Urologists Urothelial Carcinoma Working 
Group (EAU-YAU): First-line immune-checkpoint inhibitor combination therapy for chemotherapy-eligible patients with metastatic urothelial carcinoma: A systematic review and metaanalysis. Eur J Cancer 151: 35-48, 2021. PMID: 33962359. DOI: 10.1016/j.ejca.2021.03.049

8 Szabados B, Prendergast A, Jackson-Spence F, Choy J and Powles T: Immune checkpoint inhibitors in front-line therapy for urothelial cancer. Eur Urol Oncol, 2021. PMID: 33811019. DOI: 10.1016/j.euo.2021.02.010

9 Hautmann RE, de Petriconi RC and Volkmer BG: 25 years of experience with 1,000 neobladders: long-term complications. J Urol 185(6): 2207-2212, 2011. PMID: 21497841. DOI: 10.1016/j.juro.2011.02.006

10 Li W, Wang Y, Tan S, Rao Q, Zhu T, Huang G, Li Z and Liu G: Overexpression of epidermal growth factor receptor (EGFR) and HER-2 in bladder carcinoma and its association with patients' clinical features. Med Sci Monit 24: 7178-7185, 2018. PMID: 30296252. DOI: 10.12659/MSM.911640

11 Sriplakich S, Jahnson S and Karlsson MG: Epidermal growth factor receptor expression: predictive value for the outcome after cystectomy for bladder cancer? BJU Int 83(4): 498-503, 1999. PMID: 10210578. DOI: 10.1046/j.1464-410x.1999.00914.x

12 Cardillo MR, Castagna G, Memeo L, De Bernardinis E and Di Silverio F: Epidermal growth factor receptor, MUC-1 and MUC2 in bladder cancer. J Exp Clin Cancer Res 19(2): 225-233, 2000. PMID: 10965823.

13 Bellmunt J, Hussain M and Dinney CP: Novel approaches with targeted therapies in bladder cancer. Therapy of bladder cancer by blockade of the epidermal growth factor receptor family. Crit Rev Oncol Hematol 46 Suppl: S85-104, 2003. PMID: 12850530. DOI: $10.1016 / \mathrm{s} 1040-8428(03) 00067-2$

14 Li J, Jackson CL, Yang D, Noble L, Wheeler M, MacKenzie D, Adegun T and Amin A: Comparison of tyrosine kinase receptors HER2, EGFR, and VEGFR expression in micropapillary urothelial carcinoma with invasive urothelial carcinoma. Target Oncol 10(3): 355-363, 2015. PMID: 25293577. DOI: $10.1007 / \mathrm{s} 11523-014-0341-\mathrm{x}$

15 Wong YN, Litwin S, Vaughn D, Cohen S, Plimack ER, Lee J, Song W, Dabrow M, Brody M, Tuttle H and Hudes G: Phase II trial of cetuximab with or without paclitaxel in patients with advanced urothelial tract carcinoma. J Clin Oncol 30(28): 35453551, 2012. PMID: 22927525. DOI: 10.1200/JCO.2012.41.9572

16 Hussain M, Daignault S, Agarwal N, Grivas PD, Siefker-Radtke AO, Puzanov I, MacVicar GR, Levine EG, Srinivas S, Twardowski P, Eisenberger MA, Quinn DI, Vaishampayan UN, Yu EY, Dawsey S, Day KC, Day ML, Al-Hawary M and Smith DC: A randomized phase 2 trial of gemcitabine/cisplatin with or without cetuximab in patients with advanced urothelial carcinoma. Cancer 120(17): 2684-2693, 2014. PMID: 24802654. DOI: $10.1002 / \mathrm{cncr} .28767$

17 Pruthi RS, Nielsen M, Heathcote S, Wallen EM, Rathmell WK, Godley P, Whang Y, Fielding J, Schultz H, Grigson G, Smith A and Kim W: A phase II trial of neoadjuvant erlotinib in patients with muscle-invasive bladder cancer undergoing radical cystectomy: clinical and pathological results. BJU Int 106(3): 349-354, 2010. PMID: 20089114. DOI: 10.1111/j.1464410X.2009.09101.X
18 Akbari B, Farajnia S, Ahdi Khosroshahi S, Safari F, Yousefi M, Dariushnejad H and Rahbarnia L: Immunotoxins in cancer therapy: Review and update. Int Rev Immunol 36(4): 207-219, 2017. PMID: 28282218. DOI: 10.1080/08830185.2017.1284211

19 Wiley RG and Lappi DA: Targeted toxins. Curr Protoc Neurosci Chapter 1: Unit1.7, 2001. PMID: 18428453. DOI: 10.1002/ 0471142301.ns0107s14

20 Wolf P and Elsässer-Beile U: Pseudomonas exotoxin A: from virulence factor to anti-cancer agent. Int J Med Microbiol 299(3): 161-176, 2009. PMID: 18948059. DOI: 10.1016/j.ijmm. 2008.08.003

21 Michalska M and Wolf P: Pseudomonas Exotoxin A: optimized by evolution for effective killing. Front Microbiol 6: 963, 2015. PMID: 26441897. DOI: 10.3389/fmicb.2015.00963

22 Fischer A, Wolf I, Fuchs H, Masilamani AP and Wolf P: Pseudomonas exotoxin A based toxins targeting epidermal growth factor receptor for the treatment of prostate cancer. Toxins (Basel) 12(12): 753, 2020. PMID: 33260619. DOI: $10.3390 /$ toxins 12120753

23 Michalska M, Schultze-Seemann S, Bogatyreva L, Hauschke D, Wetterauer $\mathrm{U}$ and Wolf $\mathrm{P}$ : In vitro and in vivo effects of a recombinant anti-PSMA immunotoxin in combination with docetaxel against prostate cancer. Oncotarget 7(16): 2253122542, 2016. PMID: 26968813. DOI: 10.18632/oncotarget.8001

24 Sarosdy MF, Hutzler DH, Yee D and von Hoff DD: In vitro sensitivity testing of human bladder cancers and cell lines to TP40 , a hybrid protein with selective targeting and cytotoxicity. J Urol 150(6): 1950-1955, 1993. PMID: 8230543. DOI: 10.1016/s0022-5347(17)35944-x

25 Jack S, Madhivanan K, Ramadesikan S, Subramanian S, Edwards DF 2nd, Elzey BD, Dhawan D, McCluskey A, Kischuk EM, Loftis AR, Truex N, Santos M, Lu M, Rabideau A, Pentelute B, Collier J, Kaimakliotis H, Koch M, Ratliff TL, Knapp DW and Aguilar RC: A novel, safe, fast and efficient treatment for Her2-positive and negative bladder cancer utilizing an EGF-anthrax toxin chimera. Int J Cancer 146(2): 449-460, 2020. PMID: 31584195. DOI: 10.1002/ijc.32719

26 Mazor R and Pastan I: Immunogenicity of immunotoxins containing Pseudomonas exotoxin A: Causes, consequences, and mitigation. Front Immunol 11: 1261, 2020. PMID: 32695104. DOI: $10.3389 /$ fimmu.2020.01261

27 Noll T, Schultze-Seemann S, Kuckuck I, Michalska M and Wolf P: Synergistic cytotoxicity of a prostate cancer-specific immunotoxin in combination with the $\mathrm{BH} 3$ mimetic ABT-737. Cancer Immunol Immunother 67(3): 413-422, 2018. PMID: 29188305. DOI: 10.1007/s00262-017-2097-5

28 Masilamani AP, Dettmer-Monaco V, Monaco G, Cathomen T, Kuckuck I, Schultze-Seemann S, Huber N and Wolf P: An antiPSMA immunotoxin reduces Mcl-1 and Bcl2A1 and specifically induces in combination with the BAD-like BH3 mimetic ABT737 apoptosis in prostate cancer cells. Cancers (Basel) 12(6): 1648, 2020. PMID: 32580291. DOI: 10.3390/cancers12061648

Received June 15, 2021

Revised June 25, 2021

Accepted June 28, 2021 